\title{
Correction to: "His mind will work better with both of us": a qualitative study on fathers' roles and coparenting of young children in rural Pakistan
}

\author{
Joshua Jeong $^{1 *}$, Saima Siyal ${ }^{2}$, Günther Fink ${ }^{3,4}$, Dana Charles McCoy ${ }^{5}$ and Aisha K. Yousafzai ${ }^{1}$
}

\section{Correction to: BMC Public Health (2018) 18:1274 \\ https://doi.org/10.1186/s12889-018-6143-9}

After publication of the original article [1], the authors wanted to make an amendment in the Acknowledgments section as Muneera Rasheed requested to be removed. This correction article shows the original and revised version of the "Acknowledgments". The original article was not updated.

Original version: The authors thank all the individuals who participated in this study for their time and willingness to share their experiences with us. The authors thank Sadaf Lanjar and Ghullam Murtaza for data collection and transcription, Rucha Shelgikar for research assistance in data analysis, and Muneera Rasheed for assistance with translation quality checks.

Revised version: The authors thank all the individuals who participated in this study for their time and willingness to share their experiences with us. The authors thank Sadaf Lanjar and Ghullam Murtaza for data collection and transcription and Rucha Shelgikar for research assistance in data analysis.

\footnotetext{
Author details

'Department of Global Health and Population, Harvard T.H. Chan School of Public Health, 665 Huntington Avenue, 11th floor, Boston, MA, USA. ${ }^{2}$ Aga Khan University, Karachi, Pakistan. ${ }^{3}$ Swiss Tropical and Public Health Institute, Basel, Switzerland. ${ }^{4}$ University of Basel, Basel, Switzerland. ${ }^{5}$ Harvard Graduate School of Education, Cambridge, MA, USA.
}

Received: 27 November 2018 Accepted: 27 November 2018

Published online: 06 December 2018

\footnotetext{
Reference

1. Jeong J, et al. "His mind will work better with both of us": a qualitative

study on fathers' roles and coparenting of young children in rural Pakistan. BMC Public Health. 2018;18:1274. https://doi.org/10.1186/s12889-018-6143-9.
}

\footnotetext{
* Correspondence: jjeong@mail.harvard.edu

${ }^{1}$ Department of Global Health and Population, Harvard T.H. Chan School of

Public Health, 665 Huntington Avenue, 11th floor, Boston, MA, USA

Full list of author information is available at the end of the article
}

(c) The Author(s). 2018 Open Access This article is distributed under the terms of the Creative Commons Attribution 4.0 International License (http://creativecommons.org/licenses/by/4.0/) which permits unrestricted use, distribution, and reproduction in any medium, provided you give appropriate credit to the original author(s) and the source, provide a link to the Creative Commons license, and indicate if changes were made. The Creative Commons Public Domain Dedication waiver (http://creativecommons.org/publicdomain/zero/1.0/) applies to the data made available in this article, unless otherwise stated. 